\title{
LOS INDUSTRIALES CATALANES DURANTE EL FRANQUISMO
}

\author{
CARME MOLINERO \\ Universidad de Barcelona \\ PERE YSAS \\ Universidad Autónoma de Barcelona
}

\section{Introducción}

Los casi ocho lustros de la era de Franco constituyen una de las etapas fundamentales de la historia contemporánea catalana y española. Y no tanto por su amplitud cronológica como por las importantes transformaciones que cambiaron la fisonomía del país. España, en su conjunto, viviría a partir de finales de los años cincuenta una intensa industrialización, mientras que Cataluña se consolidaría como una sociedad plenamente industrial.

En los últimos años ha aumentado sensiblemente la producción historiográfica sobre el franquismo, ocupándose especialmente del estudio de la oposición política o del poder, de la política económica y de la evolución de las grandes magnitudes económicas; pero esta historiografía se ha dedicado mucho menos al estudio de la sociedad, una sociedad que cambió profundamente en casi cuatro décadas. En este artículo estudiamos un sector fundamental de la sociedad catalana - la burguesía industrial-, analizando sus organizaciones corporativas y sus actitudes y líneas de actuación durante la dictadura.

\section{La burguesía industrial catalana y el Nuevo Estado}

Al margen del mayor o menor grado de identificación de la burguesía industrial catalana con los insurrectos de julio de 1936, el inicio de la guerra civil comportó una profunda ruptura de la sociedad catalana y el alineamiento de la gran burguesía con el movimiento antirrepublicano. La revolución social, que se desarrolló en Cataluña en respuesta al fallido "pronunciamiento», imposibilitó las actitudes indefinidas o ambiguas de las clases propietarias, las cuales se vieron amenazadas política, económica y físicamente.

El triunfo franquista de 1939 significó para los industriales catalanes la restauración del orden social, lo que comportaba la recuperación de sus propiedades y de su preeminencia social. El orden burgués contaría con un 
«Nuevo Estado» que se propondría la destrucción definitiva de los movimientos sociales, políticos y culturales, que habían amenazado la hegemonía de las clases dominantes, así como de las instituciones y las agrupaciones políticas que, por su carácter democrático, habían hecho posible la acción subversiva de aquéllos.

Pero la burguesía industrial catalana estaba condenada a ocupar un espacio periférico en el nuevo bloque de poder, lo que limitaría su capacidad de influencia en los aparatos de poder político. Además, a pesar de la renuncia y condena de su pasado reciente, de su arrepentimiento por la «falsa ruta» catalanista, la burguesía catalana sería considerada por algunos sectores del nuevo régimen históricamente culpable, lo que la llevaría, por una parte, a constantes y reiteradas adhesiones al régimen y, por otra, a la renuncia de toda defensa de la identidad nacional e incluso al abandono de la propia lengua.

Las manifestaciones de gratitud hacia el régimen «restaurador» se repetirían durante los primeros años cuarenta en todas las organizaciones patronales catalanas. Así, por ejemplo, el presidente del Gremio de Fabricantes de Sabadell, durante la visita de Franco a la ciudad con motivo del tercer aniversario de la «liberación», llamaba a los industriales a «mostrar toda nuestra gratitud imperecedera al salvador de España», recordando que "después de Dios es al Generalísimo Franco y a su valeroso Ejército a quienes debemos la terminación de nuestro cautiverio y la conservación de nuestros hogares y la recuperación de nuestro patrimonio industrial» ${ }^{1}$.

Pero la adhesión al régimen franquista no se basaba sólo en la restauración del orden social, sino también en la política del Nuevo Estado, que colocaba a los propietarios en una posición de absoluta preeminencia en las relaciones sociales. Eliminados de la vida legal —muchos también de la vida «real»- todos aquellos que cuestionaban la propiedad privada de los medios de producción, integrados en la definición del «Nuevo Estado» sus valores esenciales - recordemos que el Fuero del Trabajo proclamaba que el «Estado reconoce la iniciativa privada como fuente fecunda de la vida económica de la Nación», y que "el Estado no será empresario sino cuando falte la iniciativa privada o lo exijan los intereses superiores de la Nación” ${ }^{2}-$, la burguesía

' Archivo del Gremio de Fabricantes de Sabadell (AGFS) (1942), expediente 447. Una parte notable de la documentación patronal consultada procede de organizaciones sectoriales de los industriales textiles - Gremio de Fabricantes de Sabadell, Instituto Industrial de Tarrasa, SECEA - . Ello es debido, por una parte, al papel fundamental de cste sector en la industria catalana hasta los años sesenta y su importante posición a partir de esas fechas, a pesar del protagonismo metalúrgico y del gran crecimiento de las industrias quínicas; por otra, a su larga tradición asociativa, así como a la conservación durante la post. guerra de sus tradicionales entidades, lo que aseguró una intensa vida corporativa.

'Fuero del Trabajo, XI. 
industrial pudo ocuparse de sus negocios, dejando en manos del Estado buena parte de sus antiguas preocupaciones. Así lo expresaba el citado Gremio de Fabricantès:

Descartada de nuestro sistema político de convivencia, surgido de la guerra civil, la lucha de clases, impedida por la acción del Estado la organización patronal y obrera con fines de intervención en los problemas del trabajo, erigido el Estado en ordenador y regulador de este campo y en administrador de esa difícil ciencia de la justicia social, hemos venido viviendo sin aquellas enojosas cuestiones de discusión entre representaciones patronales y obreras con sus secuelas de huelgas, lock-outs, sabotajes y perturbaciones públicas ${ }^{3}$.

Estas opiniones del Gremio de Fabricantes de Sabadell nos llevan a referirnos a un aspecto esencial de la política franquista, a veces oculto tras las referencias genéricas y superficiales al intervencionismo estatal en el plano sociolaboral y sindical, y revelador del carácter de clase del franquismo. Como es bien sabido, los sindicatos obreros fueron prohibidos, y perseguidos los núcleos clandestinos, al tiempo que se disolvían los grupos de inspiración católica, tradicionalista o falangista en la nueva Organización Sindical Españo'a (OSE), de obligatoria afiliación, y cuya finalidad principal era el encuadramiento y control de la clase obrera. Con ello se privaba a los trabajadores del instrumento esencial en defensa de sus intereses ${ }^{4}$. Contrariamente, las organizaciones patronales no fueron prohibidas, si bien tuvieron suertes diversas, y los empresarios debieron integrarse en los Sindicatos Verticales.

El Fomento del Trabajo Nacional, la máxima organización patronal catalana, no desapareció pero, reconvertida en Servicio de Alta Cultura Económica en el seno de la Organización Sindical, quedó en estado de "hibernación». Ello no supuso una modificación trascendental para la defensa de los intereses patronales, ya que, en el marco de la dictadura franquista, algunas de las funciones específicas de una organización patronal tradicional se habian convertido en innecesarias. Otras organizaciones patronales, singularmente las sectoriales, mantuvieron íntegramente sus estructuras, funciones e incluso denominación, integrándose formalmente en la estructura sindical oficial, pero con plena autonomía funcional: es el caso, por ejemplo, de las patronales laneras Gremio de Fabricantes de Sabadell e Instituto Industrial de Tarrasa. Surgieron otras organizaciones sectoriales, a partir de los años cuarenta, con, el mismo

${ }^{3}$ GFS (1936.1946), p. 2.

Sobre la OSE, véanse M. Ludevid (1976), M. Aparicio (1980) y C. Molinero y P. Ysàs (1985). 
estatus que las anteriormente citadas -el SECEA para los industriales algodoneros, la Unión Nacional de Laboratorios Farmacéuticos, que se disolverá el año 1963 con la creación de Farmaindustria, la Agrupación Nacional Autónoma de Industriales Plásticos (ANAJP) - etc. Otras entidades configuradas como sociedades de estudios fueron creadas al margen de la estructura sindical, como por ejemplo el Centro de Estudios y Asesoramiento Metalúrgico (CEAM), aunque estuvieran a niveles personales estrechamente vinculadas a la organización patronal metalúrgica del Sindicato Vertical. Es de señalar también el mantenimiento de la independencia de las cámaras de comercio e industria; la Cámara Oficial de Comercio, Industria y Navegación de Barcelona, resultado de la unificación en 1966 de las precedentes de Comercio y de Industria, desempeñaría un papel de primer orden en la representación de los intereses empresariales en el último decenio de la dictadura. Distinto carácter tendrá el Círculo de Economía - aparecido como club de opinión en 1958-, que aglutinaría a empresarios y técnicos neocapitalistas ${ }^{5}$.

Pero, contrariamente a la situación de los trabajadores, los industriales controlaron las estructuras empresariales del sindicalismo vertical -las secciones económicas, después las uniones de empresarios y los consejos de empresarios - sin interferencias relevantes de la «línea de mando» y de la burocracia azul, lo que les permitiría disponer de un instrumento de gran utilidad, especialmente como punto de apoyo en sus relaciones con la Administración.

El carácter clasista del régimen franquista quedaría de manifiesto en la legislación laboral. Las dos piezas básicas de la nueva legislación - la Ley de Reglamentaciones de Trabajo y la Ley de Contrato de Trabajo-, junto a la fijación del intervencionismo del Estado en la regulación de las condiciones de trabajo, reforzaron extraordinariamente la posición del patrón. Así, la ley de Reglamentaciones estab.ecía que el Reglamento de Régimen interior, obligatorio en todas las empresas de más de cincuenta trabajadores, y que adaptaba la reglamentación general a las condiciones y características de la empresa, era elaborado exclusivamente por el empresario - denominado significativamente «jefe de empresa»-, sin intervención directa alguna de los trabajadores ni de los organismos sindicales. Por su parte, la ley de Contrato de Trabajo reforzaba también la posición del empresario, especialmente en el aspecto disciplinario. Baste citar la redacción del artículo 72: el texto de 1931 establecía que «el deber primordial del trabajador es la diligencia en el trabajo, la colaboración en la buena marcha de la producción, del comercio o en la prosperidad de la unidad económica para quien preste sus obras y servicios»; el texto de 1944 decía que «es deber del trabajador cumplir las reglamenta-

\footnotetext{
s C. Molinero (1987).
} 
ciones de trabajo, así como las órdenes e instrucciones del jefe de empresa, de los encargados o representantes de ésta y de los elementos del personal de la misma que le asistan». Se pasaba, pues, de la diligencia a la obediencia como primer deber del trabajador en un régimen disciplinario que en otro lugar hemos calificado de cuartelario ${ }^{6}$.

Creemos insostenibles, por tanto, afirmaciones como las de Javier Tusell relativas a que

muchas de las medidas económicas de la primera etapa del franquismo como, por ejemplo, las bruscas alzas de salarios patrocinadas por Girón o incluso toda la legislación social o relativa a la Seguridad Social fueron contrarias a los intereses capitalistas o aceptadas renuenamente por ellos [y que por tanto] si por conservadurismo se entiende la dictadura del capitalismo sería inapropiado denominar conservadora a la dictadura de Franco ${ }^{7}$.

Además, referirse a las «bruscas alzas de salarios» sin mencionar los incrementos mucho mayores en los precios puede inducir a confusión: hasta 1956 los salarios reales de los trabajadores no alcanzaron el nivel de preguerra. Incluso las alzas salariales de marzo de 1956 fueron recibidas favorablemente por los industriales, interesados en el incremento de la demanda interna.

No hay que confundir las contradicciones coyunturales y secundarias entre las posiciones de las clases burguesas y las del aparato político franquista, con la no representación de los intereses del bloque dominante por el poder político. Los empresarios disfrutaron a partir de 1939 de una situación extraordinariamente favorable -incuestionabilidad del orden social, encuadramiento, control $\mathrm{y}$, en su caso, represión de los trabajadores, legislación sindical y laboral absolutamente favorable, etc.-; a pesar de lo cual no renunciaron a manifestar su descontento ante todo aquello que consideraban perjudicial para sus intereses, como determinados aspectos de la política social, entre ellos la protección del puesto de trabajo, presentada oficialmente como una gran conquista para los trabajadores y que, en realidad, formaba parte de las "contrapartidas» de carácter paternalista ofrecidas por el régimen con la voluntad de asegurar la estabilidad social, limitando los efectos perturbadores del paro y la inestabilidad laboral. Incluso algunas iniciativas legislativas provocarían una cerrada oposición patronal, como ocurrió con la creación de los Jurados de Empresa, propuesta originaria de la OSE, finalmente recogida por el Ministerio de Trabajo.

\footnotetext{
${ }^{6}$ C. Molinero y P. Ysàs (1985), pp. 113-117.

'J. Tusell (1988), p. 171.
} 
En este caso, a pesar de las limitadas atribuciones de los Jurados de Empresa y de su objetivo último - hacer efectiva la colaboración entre «el capital, la técnica y la mano de obran-, la oposición patronal a los Jurados fue frontal y logró retrasar durante seis años la aprobación del reglamento que desarrollaba la ley de agosto de 1947.

Todas las organizaciones patronales catalanas utilizaron a fondo su capacidad de presión sobre el aparato político, denunciando el carácter de «innovación peligrosísima» debido a que

la intervención obrera en la industria sea en forma de Comités de Empresa, de Control o de Gestión [...] es un procedimiento de neta inspiración marxista y ha sido considerado por altos dirigentes del comunismo internacional como el arma más eficaz para desordenar la producción industrial y preparar el asalto conista al poder ${ }^{8}$.

Entre los errores más graves señalaban, en primer lugar, el «carácter electivo, sin restricción de ninguna especie de los Jurados de Empresa», más aún considerando «el peligro que implica ir ahora a unas elecciones precisamente entre la masa obrera, entre la masa que siempre militó en los partidos de la izquierda revolucionaria» ${ }^{9}$.

Podrían reproducirse citas como la anterior hasta la saciedad; incluso de los órganos empresariales de la OSE, y de tono más subido, como el documento de la Sección Económica del Sindicato Provincial de Seguros de Barcelona, que denunciaba que la creación de los Jurados de Empresa no era «un desenvolvimiento de los previstos en el Fuero del Trabajo», sino que «constituye una reforma fundamental de las bases de nuestro derecho social hasta ahora vigente». El Fuero

elaborado en los momentos de mayor fervor patriótico del Alzamiento Nacional es no sólo el fundamento de nuestra política con las clases obreras, sino también con las dirigentes y capitalistas que dieron generosamente, como el pueblo, la sangre de sus hijos, $y$, además, aportaron los recursos económicos necesarios para sostener y ganar la guerra ${ }^{10}$.

Sin duda, la proximidad de la dura experiencia de los años de la República y de la Guerra civil y la conciencia de la existencia de un enemigo de

8 AGFS (1948), cxpediente 678.

9 AGFS (1948), expediente 678.

: AGFS (1948), expediente 678. 
clase explican, al menos en parte, la radical posición patronal. El espantajo de la «amenaza comunista» es explicable, en cambio, más que por la paranoia de algún sector patronal, porque era sin duda uno de los argumentos que más podían sensibilizar al aparato político franquista. También habría que destacar la resistencia patronal a todo intervencionismo potencialmente limitador de la libertad empresarial, especialmente si éste se desarrollaba en el mismo seno de las empresas. Finalmente, tendría que considerarse que algunos sectores empresariales podian darse cuenta de las posibilidades, no revolucionarias pero si reivindicativas y organizativas, que podian adquirir en el futuro los Jurados, desconfiando razonablemente de la capacidad de control del aparato sindical verticalista.

Cuando, finalmente, se implantaron los Jurados de Empresa -gradualmente a partir de 1954- empezaba ya a plantearse entre el empresario la necesidad de tener interlocutores válidos para negociar temas fundamentales, como la productividad, lo que daría lugar a la Ley de Negociación Colectiva de 1958, ya en el marco de una nueva política económica.

Tampoco faltaron críticas patronales a aspectos importantes de la política económica de la etapa «autárquica». Efectivamente, ya desde finales de los años cuarenta, las organizaciones de los industriales catalanes fueron dibujando una línea crítica al elevado grado de intervencionismo estatal en la economía, responsabilizándolo en buena parte de los problemas más graves -materias primas, energía, comercio exterior-, y de defensa paralela de un modelo más liberal, más acorde con la ortodoxia capitalista. Sin embargo, esta crítica, y las propuestas alrernativas que la acompañaban, eran muchas veces considerablemente contradictorias, ya que se basaban en una extremada parcelación de la realidad. Así, lejos de formular unas propuestas alternativas coherentes, los industriales, muchas veces, pedían intervención o desregulación, en función de sus intereses al más corto plazo ".

Hay que tener en cuenta, además, que la mayoría de industriales se adaptaron rápidamente a las nuevas condiciones de posguerra. Puede hablarse incluso de un «empresario de la autarquía» para referirse no sólo al de los negocios fáciles de los años cuarenta, especializado en vender su cupo de materia prima, en traficar con las licencias de importación o en colocar parte sustancial de su producción en el mercado negro, sino también al acostum-

"No hay que insistir, por otra parte, en el hecho que las organizaciones patronales no efectuaron ninguna crítica al intervencionismo estatal, que privaba a los trabajadores de toda posibilidad de asociación autónoma y que fijaba las condiciones de trabajo, librando a las empresas de «aquellas enojosas cuestiones de discusión entre representantes patronales y obreros», como decía el GFS. Este intervencionismo aportaba, además, otras ventajas como unos salarios reglamentados bajisimos, ante los que muchas empresas podían desarrollar políticas "paternalistas», estableciendo complementos salariales para incrementar unas retribuciones casi por debajo del nivel de subsistencia. 
brado a disfrutar de un mercado absolutamente protegido, donde podia vender sus mercancías sin preocuparse de la eficiencia de la unidad productiva, poco o nada interesado en la exportación, acostumbrado a aumentar los beneficios mediante la consecución de ventajas administrativas, y a no tener que preocuparse - sólo excepcionalmente - de la conflictividad laboral. Unos y otros disfrutaron de una auténtica «edad de oro", aunque este tipo de empresarios necesitaría reconvertirse profundamente al final de la década de los cincuenta.

Con todo, las organizaciones representativas del empresariado catalán defendieron con creciente firmeza la necesidad de una «liberalización económica». Un informe de la Sección Económica del Sindicato Provincial de Transportes y Comunicaciones de Barcelona, fechado en noviembre de 1948, ampliamente difundido entre las entidades empresariales catalanas, recogía buena parte de las preocupaciones y críticas patronales ante la siruación económica, empezando por el insuficiente abastecimiento de materias primas, el tráfico en el mercado negro, los recargos en los costes de producción (como consecuencia de los seguros sociales, la cuota sindical, etc.), el crecimiento de la burocracia, y se ocupaba especialmente del excesivo intervencionismo económico, tanto por su carácter perjudicial para la economía como por lo que significaba de "procedimiento socializante, contrario al principio de la iniciativa privada y de la libre empresa». La iniciativa privada -añadía-

ha sido siempre a través de la historia fuente inagotable de progreso y por tanto todo lo que vaya en contra de la «empresa libre» serả siempre perjudicial en el terreno de la economía.

El documento criticaba, finalmente, las decisiones gubernamentales tomadas sin consultar a los sindicatos,

pues los sindicatos representan los diferentes sectores de la Economía del país, y por esta razón deberán siempre ser consultados antes de dictarse una disposición legal que afecte a las industrias por ellos representados ${ }^{12}$.

Por su parte, las Cámaras de Comercio e Industria de Cataluña y Baleares aprobaron, en octubre del mismo año, otro informe en el que, "como resultado del examen de la situación económica y de las tendencias observadas en el desenvolvimiento industrial y mercantil», creían «llegado el momento de orientar la política económica hacia el retorno de la libertad en el ejerci-

12 Archivo de Transportes Municipales de Barcelona, Sindicato Provincial de Transportes y Comunicaciones de Barcelona (1948). 
cio de aquellas actividades» ${ }^{13}$. Ante estas críticas, el ministro de Industria y Comercio, Juan Antonio Suanzes, declaraba que el gobierno era antiintervencionista

en cuanto conoce perfectamente los defectos y los inconvenientes del sistema, repugna las intervenciones no indispensables en cuanto traban y frenan la libre actividad y sabe muy bien que, en líneas generales, la prosperidad está en razón inversa a la extensión del intervencionismo.

Pero Suanzes se mostraba también contrario al modelo liberal previo a 1936: «un siglo de "dejar hacer", de "dejar pasar" nos llevaron a 1936, ¿no es perfectamente justificado que en economía como en tantas otras cosas, utilicemos nuevos métodos, nuevos sistemas, sin cerrarnos a tópicos o frases con mucha más fachada que contenido?» ${ }^{14}$. En noviembre de 1949 era la Comisión Permanente del Consejo Económico Sindical de la provincia de Barcelona quien, en un documento dirigido a Franco, se quejaba del problema de la distribución de materias primas vinculándolo directamente al intervencionismo, al tiempo que repasaba el conjunto de problemas de la economía catalana, entre ellos, sin citarlo, el centralismo administrativo, proponiendo ampliar las facultades de la delegación regional de comercio, para facilitar a la industria catalana «un desarrollo coordinado de la exportación y la importación, sobre todo la de carácter temporal que cumple el fin de transformar las importaciones en productos manufacturados, aceptados en el mercado exterior». El documento solicitaba también una mayor participación de los industriales en las decisiones económicas:

entendemos sería de interés cuando las circunstancias lo requieran, que los ministerios consultaran industriales de reconocido criterio y buena fe de Jas Juntas Económicas de los Sindicatos ${ }^{15}$.

La presión patronal a favor de la liberación económica aumentó a partir de 1950. En el informe titulado «Consideraciones acerca de la futura ordenación de la industria lanera» se decía: «El actual sistema de intervención resulta ya inadecuado para encauzar debidamente el normal desarrollo del comercio e industria», por «el carácter de ficción que representa el mante-

13 Cámara Oficial de Comercio y Navegación de Barcelona (COCNB) (1948), p. 15.

14 Fomento de la Producción (1948), núm. 69. de 1949

is Comisión Permanente del Consejo Económico Sindical de Barcelona, noviembre 
nimiento de unos precios de tasa de la lana», por imposibilidad del industrial «de poder fabricar dentro de la ley una gran cantidad de tipos que el mercado acepta y consume y que deben ser vendidos en régimen de clandestinidad, mientras que el público rechaza la adquisición de muchos artículos que se le ofrecen por debajo de los precios o tipos legales» y porque, en definitiva, ante

la complejidad de factores que intervienen en el comercio de la lana y en el proceso industrial de sus manufacturas, cualquier sistema de intervención y control que pretenda ser realmente eficaz, comporta necesariamente un complicado mecanismo de reglamentación, tramitación y fiscalización que fatalmente tiene que dificultar las actividades de contratación, recogida y transformación de la materia primera.

Ante esta situación, la única alternativa, unánimemente compartida por todo el sector industrial lanero es la libertad total del comercio e industria de la lana, tanto por lo que respecta a las primeras materias como a sus manufacturados, hilados y tejidos, y al comercio de los mismos, pues únicamente dentro de un régimen de libertad podría ser encauzado el necesario reajuste de los precios de las materias primas y sus productos elaborados, de acuerdo con las realidades y necesidades del mercado consumidor ${ }^{16}$.

El gobierno formado en julio de 1951 impulsó una política liberalizadora que dio satisfacción parcial a algunas de las demandas de los industriales. La memoria del Gremio de Fabricantes de Sabadell de 1952 destacaba que

si en el plano nacional es el año de la reconquista porque el mundo de más acá de los telones ha entrado por las vías de la amistad y del franco deseo de las buenas relaciones con España [...] en el de la vida económica es el año de la libertad, después de tantas intervenciones como siguieron a nuestra guerra de liberación ${ }^{17}$.

Pero otros problemas quedaban sin solución satisfactoria. La Cámara de Comercio y Navegación de Barcelona planteaba, en una carta al Ministro de Comercio, la simplificación del «régimen bajo el cual se realiza actualmente nuestro comercio exterior». Sería deseable, decía la Cámara,

16 AGFS (1950), expediente 712.

"GFS (1952). 
que pudiesen ser obviadas las dificultades que ocasiona la inevitable lentitud con que ha de operar por las varias y diversas interferencias, directas e indirectas, que padece nuestro comercio exterior, [entre ellas] las derivadas del sistema plural de cambios actualmente en vigor, que ocasiona grandes trastornos y perjuicios e impide a buen seguro su desarrollo.

\section{La Cámara recomendaba evitar}

que la peseta tenga distinto valor, no sólo por lo que se refiere a las divergencias que se observan entre los mercados exteriores y el interior, sino también por su repercusión en la determinación de los precios de diferentes productos y mercancías ${ }^{18}$.

En una iniciativa sin precedentes, en noviembre de 1954 , los presidentes de las corporaciones económicas de Barcelona se reunieron con el gobernador civil, Felipe Acedo, para transmitirle las aspiraciones de la burguesía catalana en el terreno económico. Participaron en la reunión Miguel Matéu Pla, presidente del Fomento del Trabajo Nacional; Ramón Par, presidente de la Cámara de Industria; Félix Escalas, presidente de la de Comercio y Navegación; Felipe Bertrán Güell y José Valls Taberner, presidente y vicepresidente, respectivamente, de la Sociedad Económica de Amigos del País; Angel Traval, presidente de la Cámara de la Propiedad Urbana; Jesús Mir, presidente de la Cámara Minera; José de Fontcoberta, marqués de Villalonga, presidente del Instituto Agrícola Catalán de San Isidro, y el delegado de Sindicatos José Antonio Parera. Entre las demandas planteadas destaca la reducción de «las intervenciones que dificultan la libertad de comercio necesaria para su desarrollo" y las relativas a las necesidades infraestructurales catalanas: ferrocarriles, carreteras, puerto de Barcelona, etc. ${ }^{19}$.

La coyuntura de los años 1956-1957 --movilizaciones obreras y estudiantiles, crisis política, desbarajuste económico, cambio gubernamental- fue seguida de manera expectante por los industriales. Los primeros aumentos sa!ariales de 1956 fueron valorados favorablemente, pero no así los de octubre ${ }^{20}$. En cambio los empresarios obtuvieron, después de reiteradas peticiones -la Junta del SECEA había insistido ante el Director General de Trabajo a finales de 1955 sobre la necesidad de «mantener o restablecer la disciplina en el trabajo con posibilidad, aunque limitada y justificada, de los despi-

${ }^{18}$ COCNB (1954-1956).

19 COCNB (1954-1956).

${ }^{20}$ SECEA, Acta de la reunión de la Junta de Gobierno de 10 de octubre de 1956, y COCINB (1957). 
dos" ${ }^{21}$-, una flexibilización limitada de la legislación relativa al despido, facilitándolo en dos aspectos: suprimiendo el expediente previo y posibilitándolo incluso sin causa justificada, simplemente mediante una indemnización para el trabajador. El decreto de 26 de octubre de 1956 fue valorado muy favorablemente, a pesar de que aún no establecía «un régimen de libertad de contratación ni un fácil recurso al despido sin causa» ${ }^{22}$.

El Gremio de Fabricantes de Sabadell llamaba la atención de las empresas «porque el uso inteligente y sereno del instrumento que el nuevo sistema supone y representa tiene importancia destacada y trascendencia nada despreciable» ${ }^{23}$, mientras que la Cámara de Comercio de Barcelona consideraba que el decreto no había de ocasionar «trastornos de ninguna clase, pues la Cámara supone razonablemente que los empresarios sabrán hacer discreto uso de las facultades que les han sido reconocidas" ${ }^{24}$.

El nuevo gobierno formado en febrero de 1957 fue muy bien acogido por las entidades patronales. La Junta de gobierno del SECEA se manifestó rápidamente «bien impresionada por el nuevo gobierno", acordando entrevistarse con los nuevos ministros para

tener un cambio de impresiones sobre los problemas de esta industria que en principio quedan resumidos en el deseo general [...] de que se supriman o desaparezcan las intervenciones de los ministerios en los órganos económicos y en el comercio en general, de que se procure la posible liberalización y descentralización de los trámites y de que se fomenten las exportaciones de excedentes ${ }^{25}$.

Las entrevistas fueron muy satisfactorias para los industriales algodoneros; el ministro Ullastres les manifestó que el Ministerio de Comercio se hallaría «al servicio de los industriales y comerciantes privados», que su política sería «satisfacer los intereses privados», y el ministro de Trabajo, Sanz Orrio, se comprometió a consultar antes de cualquier decisión «a los representantes oficiales de nuestra industria». Por todo ello, los industriales algodoneros consideraban que «hay razones para mostrar satisfacción ante el nuevo gobierno», ya que no dudaban de su interés en «incrementar la exportación y procurar en general una liberalización del comercio» y vigilar «las inversiones estatales». Todo ello, concluían, «es la base de una buena políti-

"SECEA, Acta de la reunión de la Junta de Gobierno de 2 de diciembre de 1955.

${ }^{22}$ GFS (1956).

${ }^{23}$ GFS (1956).

24 COCNB (1957).

${ }^{25}$ SECEA, Acta de la reunión de la Junta de Gobierno de 6 de marzo de 1957. 
ca" ${ }^{26}$. Dos años después, los industriales catalanes manifestarían reiteradamente su acuerdo con el conjunto de medidas incluidas en el Plan de Estabilización, a pesar de que para muchas empresas representara una condena de desaparición, porque

es incuestionable que el desarrollo de la economía mundial y, concretamente, europea, a la que estamos ligados sin posibilidad de aislamiento, impedía demorar esta adaptación que el Gobierno ha iniciado con el aplauso general y con el deseo unánime de que llegue hasta las últimas consecuencias ${ }^{27}$.

\section{Los industriales en la etapa desarrollista}

Para los industriales catalanes, la nueva política económica iniciada a finales de los años cincuenta significó un cambio que sintonizaba plenamente con sus aspiraciones. El «desarrollo» era sinónimo de industrialización; la política económica del Estado cambió el eje del discurso económico, produciéndose un desplazamiento en sus contenidos de base agrarista a favor del industrialismo, y de carácter autárquico e intervencionista, en favor de principios liberales, acentuando el papel de la iniciativa privada y de «libre empresa». Por primera vez desde 1939 la burguesía industrial catalana conectaba plenamente con las líneas maestras de la política económica propugnada por el Gobierno, lo que se tradujo en un explícito y reiterado apoyo de las organizaciones empresariales catalanas e, incluso, en la incorporación de personas vinculadas a estas organizaciones en los equipos económicos gubernamentales.

Pero la liberalización económica pondría de manifiesto las contradicciones existentes entre los dirigentes de las organizaciones empresariales, que defendían que la libertad económica no podía tener limitaciones, y muchos empresarios que, atendiendo exclusivamente a sus intereses a corto plazo, demandaban mayor cota de libertad cuando les convenía y acentuación de la intervención protectora cuando veían amenazados sus intereses ${ }^{28}$. El boletín del SECEA se ocupaba de ello en septiembre de 1961:

Un aspecto realmente importante de la vida económica, en relación al cual han cristalizado actitudes de corto alcance, es el que

${ }^{26}$ SECEA, Acta de la reunión de la Junta de Gobierno de 6 de marzo de 1957.

${ }^{27}$ SECEA, Boletin Informativo, núm. 117, 25-7.1959.

28 Estas actitudes aparecen especialmente en las actas de las Secciones Económicas y Uniones de Empresarios de los Sindicatos, especialmente en los informes relativos a nuevas instalaciones industriales. 
se refiere a los complejos problemas que suscita la tendencia liberalizadora que anima la política económica del gobierno. Hemos de comprender que la libertad económica es una e indivisible y que si la adoptamos, hemos de estar dispuestos a arrostrar todas sus consecuencias. No es posible parcelar la libertad económica reservándola para los sectores en que nos favorezca, y rechazarla en aquellos aspectos en que pueda parecernos perjudicial a nuestros intereses. La incompatibilidad de ambas actitudes no sólo es de orden lógico, sino que procede primordialmente de los imperativos inherentes al funcionamiento de la economía. Y ésta es una verdad elemental que hemos de estar dispuestos a aceptar íntegramente ${ }^{29}$.

Sin embargo, «esas actitudes de corto alcance» ni desaparecerían con facilidad ni afectarían a sectores reducidos del empresariado industrial.

La identificación de las organizaciones corporativas de los industriales con la política liberalizadora y desarrollista no era óbice para que, en determinadas coyunturas, esas organizaciones manifestaran sus desacuerdos. Así, la recesión de 1967-68 provocó numerosas críticas de los industriales a la acción gubernamental, a la cual se hacía responsable de los estrangulamientos financieros y de los desajustes productivos que sufrieron buena parte de las empresas. Buena parte de las inversiones se habían dirigido a proyectos industriales de rentabilidad inmediata, descuidando las inversiones agrícolas y de infraestructura. La desproporcionada asignación de recursos provocó un conjunto de desequilibrios que forzaron aumentos en las importaciones, sobre todo de alimentos, que saldaron con la partida de invisibles hasta 1965 , fecha a partir de la cual fueron necesarias medidas de desaceleración. Para el Gremio de Fabricantes de Sabadell nadie se había preocupado, y menos los responsables de la economía, al contrastar los datos reales con las cifras previstas en el Plan de Desarrollo, «de sacar las consecuencias debidas y aplicar los remedios convenientes, para subsanar el desajuste que se estaba produciendo", y por el contrario se consideró el mayor crecimiento "como un éxito suplementario de nuestra economía que permitiría quemar etapas» en la marcha hacia el desarrollo» ${ }^{30}$.

Las medidas gubernamentales -devaluación de la peseta, contención del gasto público, congelación salarial-, aunque aceptadas globalmente, recibieron críticas de algunos sectores. Así, mientras la Cámara de Comercio e Industria de Barcelona se mostraba de acuerdo con la congelación salarial y propugnaba

20 SECEA, Boletin Informativo (1961), núm. 163.

${ }^{30}$ GFS (1968). 
una descongelación gradual, la Unión de Empresarios del metal barcelonés la criticaba y el Consejo Nacional de Empresarios señalaba que

nuestra industria no será más competitiva si no se utiliza en una medida óptima su capacidad. Para ello se requiere un tirón de la demanda, cuyo renglón más decisivo es el mercado interior, con sus treinta y tres millones de consumidores. Por eso, y por razones de justicia, hemos defendido la descongelación ${ }^{31}$.

Adicionalmente, algunos sectores empresariales empezaban ya a apuntar prob'emas y a proponer soluciones de mayor alcance: se trataba, en definitiva, de dotar a la política económica gubernamental de una perspectiva a largo plazo. Para la revista del Fomento del Trabajo Nacional

las reformas que exige la economía española son muchas: desde la reordenación del campo a la normalización del mercado financiero, pasando a la reestructuración industrial y los problemas del comercio exterior; pero para abordarlos no basta aprovechar el dictado de unas medidas coherentes con una devaluación, sino que se hace preciso establecer un verdadero programa de actuación que se encamine no a superar unos momentos críticos, sino a dar orientación definitiva a la economía española ${ }^{32}$.

A partir de mediados de los años sesenta, buena parte de los planteamientos de las organizaciones empresariales sobre el futuro de las economías catalana y española fueron realizados teniendo presente la posible incorporación española a la Comunidad Económica Europea. El apoyo al ingreso español en el Mercado Común era prácticamente unánime en las entidades empresariales, pero ambiguo en buena parte del empresariado. Por otra parte, la integración no tenía la misma significación para todos sus defensores: para unos, era un tema exclusivamente económico; para otros, tenía unas innegables connotaciones políticas. Estos últimos eran los que, preocupados por adelantarse a los acontecimientos, comenzaban a buscar, ya en aquellas fechas, una vía de sustitución del régimen franquista que asegurara la plena estabilidad del orden social y económico. Pero para buena parte de empresarios, los aspectos económicos eran los únicos a considerar y, por tanto, las

"Archivo de la Corona de Aragón (ACA), Delegación Provincial de Sindicatos (DPS), Acta del Pleno del Sindicato Provincial del Metal de 11-1-68, y Archivo General de la Administración (AGA), Delegación Nacional de Sindicatos (DNS), Nota del Consejo Nacional de Empresarios, Caja 18.

32 El Trabajo Nacional, 10 de diciembre de 1967. 
condiciones de la integración eran fundamentales para apoyar o rechazar un posible acuerdo.

El Círculo de Economía, como grupo de opinión y relación, y la Cámara de Barcelona, como entidad representativa, fueron los máximos impulsores de la opción favorable a la incorporación española a la CEE, si bien desde ópticas no plenamente coincidentes. Carlos Ferrer Salat decía en diciembre de 1967 desde la tribuna del Círculo de Economía: «es necesaria la integración espanola a Europa, es indispensable para poder competir»; pero «también con esta integración podremos nosotros conseguir una mayor estabilidad política en el futuro y un mayor equilibrio y progreso social» ${ }^{33}$. Un año después, esta vez desde la prensa, Ferrer Salat insistía en la dimensión política de la integración: «Integrarse a un conjunto de países que tienen una notable estabilidad social.y política tranquiliza considerablemente nuestras profundas inquietudes ante nuestro futuro político y social» ${ }^{34}$. En cambio, Andrés Ribera Rovira, presidente de la Cámara de Barcelona, en 1972 planteaba que la «integración es irreversible», pero matizaba: «pensamos en Europa como el único camino a seguir» por «motivos económicos» ${ }^{35}$.

La postura de aquellos sectores patronales sin «inquietud» ante el futuro político y social, para los cuales el franquismo seguía siendo el régimen que mejor aseguraba sus intereses en el presente y en el futuro, queda reflejada en el documento del Consejo Nacional de Empresarios de octubre de 1969, en el que, si bien se aseguraba la voluntad de "vincularnos al Mercado Común» y de hacer «lo posible para que esta aspiración culmine en resultados positivos, $[\ldots]$ nos opondremos a que el Tratado empeore el estado actual y futuro de nuestra economía» ${ }^{36}$. Lo anterior explica el tibio apoyo de las organizaciones empresariales al Tratado Preferencial de 1970 y su abierta crítica a la falta de transparencia en la negociación.

Sin embargo, para reforzar las posiciones favorables a la plena integración, el Círculo de Economía preparó en 1972 un documento en el que, entre otras cosas, se decía que la incorporación de España, en calidad de miembro de pleno derecho, a la Comunidad Económica Europea «constituye una exigencia histórica a la que urgentemente es necesario adaptarse con carácter prioritario». El retraso en el ingreso, añadía, «crea una gran incertidumbre en la toma de decisiones empresariales» y entraña riesgos evidentes. Firmaron el documento, además del Círculo de Economía, 12 de las organizaciones más representativas de Cataluña: CEAM, SECEA, Gremio de Fabricantes de

33 Archivo del Círculo de Economía (ACE); C. Ferrer Salat, «Integración a Europa", dentro de La problemática económica de Cataluña, diciembre de 1967.

34 C. Ferrer Salat, «Hacia una Cataluña moderna”, Diario de Barcelona (1969), número extraordinario de febrero.

${ }^{33}$ COCINB (1972).

${ }^{36}$ AGA, DNS, Nota del CNE, 25 de octubre de 1969, Caja 17. 
Sabadell, Instituto Industrial de Tarrasa, Colegio del Arte Mayor de la Seda, Servicio de Comercio de Empresarios Sederos, Instituto de Estudios Europeos, Sociedad Barcelonesa de Amigos del País, Instituto Agrícola Catalán de San Isidro, Fomento del Trabajo Nacional, Asociación Cristiana de Dirigentes y Liga Europea de Cooperación Económica.

Hay que decir, sin embargo, que algunas de las entidades firmantes lo hicieron sólo con la conformidad de los organismos directivos y sin reflejar el sentimiento de buena parte de sus bases. Donde sí se produciría, en cambio, una completa coincidencia entre el conjunto de los industriales y los dirigentes de las organizaciones representativas era en el rechazo de determinados aspectos de la política económica «desarrollista», como la creación de polos de desarrollo, presentados oficialmente como un paso necesario en la racionalización y reequilibrio del territorio. Esta política no era cuestionada en lo relativo a sus planteamientos programáticos, pero sí en la práctica. Pere Durán Farell, en una conferencia en el Círculo de Economía, manifestaba que

s'ha de fer una politica d'enfortiment de les zones industrialitzades, perquè la industria transformadora que exigeix una mà d'obra especialitzada i abundant, que dóna un gran valor afegit, que és el que ens interessa precisament, no es troba ni a Burgos, ni a Sevilla ni a La Coruña, es troba a Barcelona i Bilbao ${ }^{37}$.

En lo referente al sector público de la economía española, si el Círculo de Economía trató de definir el papel del INI, la mayoria de los industriales simplemente manifestó su oposición a la competencia desleal de las empresas púb'icas; cuya existencia sólo consideraban justificada cuando la iniciativa privada no era capaz de cubrir un determinado espacio en el mercado.

Para los industriales catalanes, críticos también con la política gubernamental con respecto a la industria básica, se descuidaba el apoyo a la industria transformadora y, especialmente, a las infraestructuras que ésta necesitaba. Por ello, a través del Consejo Económico Sindical de Cataluña, presidido por Andrés Ribera Rovira, canalizaron sus propuestas en asuntos como el puerto de Barcelona, el trasvase del Ebro, las vías de comunicaciones o la localización de nuevos complejos industriales, mientras que desde otras instancias se denunciaban los problemas derivados del «caos urbanístico y de planteamiento" del Area Metropolitana de Barcelona ${ }^{38}$, y la especulación del suelo, partiendo de la consideración que el 30 por 100 de los costes de una nueva inversión industrial en el entorno de Barcelona correspondía a la compra del

${ }^{37}$ ACE; P. Durán FArEll, «L'economia espanyola als anys setanta», 7 de julio de 1970 (mecanografiado).

${ }^{38}$ Círculo de Economía (1972). 
terreno. Sin embargo, sorprendentemente los dirigentes empresariales presentaban la especulación como un fantasma, fragmentando la realidad y, por consiguiente, silenciando que los propios industriales participaban frecuentemente en negocios inmobiliarios especulativos.

La fragmentación de la realidad a la que acabamos de aludir era especialmente clara en lo relativo a las relaciones laborales, terreno, además, en el que se agudizaban las contradicciones dentro del empresariado industrial. El Círculo de Economía, coherente con su defensa del modelo liberal, había defendido desde fecha tan temprana como 1965 la necesidad de ampliar al máximo el cuerpo negociable entre empresarios y trabajadores, si bien obviando el problema de la representatividad de los últimos. Esta postura sería adoptada más tardíamente por las organizaciones patronales más importantes. Pero en el marco de las elecciones sindicales de 1966, que supusieron un importante impulso al movimiento de Comisiones Obreras, el Consejo Nacional de Empresarios, como habían hecho las organizaciones catalanas, llama: ba a vigilar «toda organización contraria a la Organización Sindical, absteniéndose los empresarios de utilizar otro cauce ajeno a la misma y negándose al diálogo con aquéllos que, carentes de la normal representatividad, pretenden atribuirse facultades que tienen un origen ilegal o clandestino» ${ }^{39}$, y el Instituto Industrial de Tarrasa se quejaba de la normativa electoral que podía provocar que «salgan elegidos no los mejores, que fue el eslogan de la pasada campaña electoral, sino los peores, entendido en el sentido de que puedan salir elegidos en algunos casos aquellos trabajadores con antecedentes laborales desfavorables que figuraban excluidos en la anterior legislación» ${ }^{40}$.

Así, en el mes de agosto de 1968 Andrés Ribera Rovira, en su habitual correspondencia con el Gobernador Civil de Barcelona, aconsejaba que la negociación de los convenios colectivos se realizara en el ámbito provincial, e incluso nacional, para combatir «los esfuerzos que los grupos obreros marginales a la Organización Sindical pueden desplegar en favor de los convenios de empresa, dado que es precisamente en este ámbito (en las empresas) donde pueden ejercer su influencia, imposible de desarrollarse en ámbitos más amplios a los que no tienen acceso" ${ }^{41}$. Es decir, se trataba de evitar que los convenios fueran negociados por los Jurados de Empresa, elegidos directamente por los trabajadores y único nivel representativo de la OSE, para serlo por los órganos sindicales controlados por la «línea de mando».

Desde la segunda mitad de los sesenta fue aumentando la preocupación patronal ante el aumento de la conflictividad laboral. Después de varias dé-

\footnotetext{
${ }^{39}$ AGA, DNS, Comisión Permanente de CNE, 21 de julio de 1966, Caja 25.

40 Archivo Instituto Industrial de Tarrasa (AIIT), Correspondencia 1966.

${ }^{41}$ Archivo del Gobierno Civil de Barcelona (AGCB), Archivo de Gobernadores, Expediente 1321.
} 
cadas, los empresarios debían ocuparse de nuevo de estas «enojosas cuestiones». El Consejo de Empresarios de Barcelona se quejaba de la «ausencia de autoridad» y manifestaba que la «negociación colectiva, si ha de ser eficaz, ha de realizarse sin la existencia de [...] presiones» ${ }^{42}$, y el Consejo Nacional, a su vez, expresaba «la preocupación que en el empresariado español causan los hechos que vulnerando el orden público [...] alteran la paz orgull:o de nuestro régimen", por lo cual recababan "del poder público la mayor intensificación en las medidas que para combatir estas alteraciones fueren menester ${ }^{43}$. En una carta al Delegado Provincial de Sindicatos de Barcelona, un grupo de empresarios del metal manifestaba la necesidad de «convencer a nuestro Gobierno que actúe con mayor energía», al tiempo que se ofrecían para «insinuar pistas e informaciones para que la autoridad pueda actuar e investigar actividades fuera de la empresa». Se trataba de desarrollar una acción política que "garantice el libre ejercicio empresarial, la total tranquilidad socioeconómica y la sana esperanza en el futuro del país» ${ }^{44}$.

Por tanto, teniendo en cuenta estas posturas, no ha de extrañar que la forma habitual de afrontar la conflictividad en la mayor parte de las empresas fuera la represión laboral —sanciones, despidos - y, cuando era necesaria, política, mediante la utilización de las fuerzas policiales. A pesar de importantes victorias obreras en cuanto a las reivindicaciones planteadas, pocas movilizaciones finalizaban sin un elevado coste en sancionados, despedidos o encarcelados. Menos ha de sorprender, pues, que para algunos sectores populares fuera un término empresario equivalente a «franquista».

Otras dos cuestiones fueron objeto de especial atención por parte del empresariado durante estos años: la flexibilización del mercado de trabajo y la participación de los trabajadores de las empresas. Desde el Círculo de Economía a los Consejos de Empresarios se acentuó la demanda de «flexibilización de p!antillas» argumentando que «no se pretende abuso o libertinaje para el despido, sino que, mediante el oportuno expediente, se pueda proceder a la adecuación de la plantilla de obreros cuando se modernice sus instalaciones» ${ }^{45}$; o que

el pleno empleo es, en último término, un objetivo del Estado y no de cada empresario particular [y] en la medida en que se acepta y funda el orden social en éstos - los empresarios- no puede el Estado recortar su libertad de acción en terreno tan

12 ACA, DPS, Acta del Consejo Provincial de Empresarios de 13 de marzo de 1970, Caja 197

3 AGA, DNS, Nota del CNE 6-2-73, Caja 13.

"Carta de empresarios del metal al Delegado de Sindicatos de Barcelona (1971), citada a J. M. Huertas (1982).

4s ACA, DPS, Sindicato del Metal, Caja 2314. 
primario como es la consecución de los más altos niveles de productividad de los factores de producción ${ }^{46}$.

En definitiva, se pedía coherencia entre la política económica y el marco de relaciones laborales; lo que no se demandaba, en cambio, era coherencia entre la ampliación de la libertad económica y la falta absoluta de libertades politicas.

La oposición a la participación de los trabajadores en las empresas, o a la simple ampliación de las facultades de los enlaces sindicales y Jurados de Empresa, fue otra problemática que generó tensiones entre el empresariado industrial y el poder político. La Sección Económica del Sindicato Textil de Tarrasa rechazaba rotundamente «toda intromisión de la representación sindical obrera que pueda afectar la natural facultad de total organización del trabajo por parte del empresario ${ }^{47}$, y el Consejo de Empresarios de Barcelona acordaba que «no debe abdicarse del principio de que la organización del trabajo es facultad exclusiva del empresario, con el máximo respeto a los derechos de los trabajadores, pero privativo de la empresa» ${ }^{48}$.

Se estaba así iniciando un enfrentamiento, que se radicalizaría en los años siguientes, entre los empresarios y el aparato del Movimiento. Este, buscando su propia supervivencia, pugnaba por preservar la estructura y funciones de la OSE, aceptando, si era necesario, aquellas reivindicaciones de los trabajadores que no implicaban su cuestionamiento; entre ellas, por ejemplo, la participación obrera en la empresa, mayores atribuciones a enlaces y Jurados y mayor protección legal a éstos. Los industriales, en cambio, en un contexto de creciente conflictividad, estaban dispuestos a ceder ante reivindicaciones laborales como aumento de salarios y en aspectos inaceptables para el sindicalismo vertical —unas relaciones laborales más libres-, pero no a ceder en los principios esenciales de la «libre empresa».

\section{Los industriales ante la crisis económica y la crisis politica}

El impacto de la crisis económica mundial, el incremento de la conflictividad laboral y la incertidumbre política provocaron el hundimiento de las expectativas empresariales. Contra lo que reiteradamente se ha dicho, no fue responsabilidad exclusiva del aparato político franquista el aplazamiento de decisiones económicas ante la crisis. I.os empresarios, atemorizados ante el peligro de una crisis social aguda, presionaron para «mantener el nivel má-

* Círculo de Economía, La política económica a examen, abril 1969.

" AIIT, Sección Económica del Sindicato Local Textil.

${ }^{4}$ ACA, DPS, Acta del CPE de Barcelona, 23 de diciembre de 1970, Caja 13. 
ximo de empleo aun a costa de hacer más irracional la economía de mercado» ${ }^{49}$. La Cámara de Barcelona, en un informe dirigido al Gobierno, señalaba claramente que

el problema más preocupante que puede plantearse es el de los efectos sociales por descenso de la actividad económica; [por ello] se estima que los principales esfuerzos inmediatos deben orientarse a evitar el desempleo y la reducción de la capacidad adquisitiva de la población afectada ${ }^{50}$.

Paralelamente, el aumento de la conflictividad laboral llevaba, finalmente, a la mayoría del empresariado industrial a pronunciarse por un cambio profundo en las relaciones laborales, implantando unas «reglas de juego que sean aceptadas por todas las partes interesadas en el proceso económico a fin de dar estabilidad al sistema socioeconómico del país" ${ }^{51}$. El nuevo marco laboral debía reconocer el derecho de los trabajadores a elegir sus propios representantes, así como el derecho de huelga, pero en contrapartida debía asegurar plenamente la absoluta autoridad patronal en la empresa. En este punto se radicalizaron los enfrentamientos con el aparato del Movimiento, ya que éste no dudó incluso en recurrir a la tradicional demagogia «anticapitalista». Un punto central de confrontación fue la Ley de Relaciones Laborales, cuyas consecuencias, para los industriales metalúrgicos de Barcelona,

darán al traste con el desarrollo económico en cuanto irrogarán irreparables perjuicios a la iniciativa privada, a la economía de mercado y, por ende, a la empresa, motor máximo del quehacer y sustento del entramaje social y productivo $^{52}$.

Andrés Ribera Rovira, en carta al presidente del Consejo Nacional de Empresarios, llegaría a advertir que la estabilidad política del país peligraba, no sólo por la acción de la oposición antifranquista, sino también por la retirada de confianza de aquellos que habían sostenido al régimen ${ }^{53}$.

Cuando los industriales se manifestaban tardíamente partidarios de que los trabajadores tuvieran unos mínimos derechos, se encontraban enfrentados con parte del aparato del Movimiento, así como con una movilización de

\footnotetext{
Economia (1974), núm. 1846.

so COCINB (1975).

51 AGA, DNS, Informe del CPE de Barcelona, julio de 1975, Caja 41.

52 ACA, DPS, Comisión Permanente de la Unión de Empresarios del Metal, 6 de oc. tubre de 1975 .

${ }^{53}$ AGA, DNS, CNE, Carta de 9 de julio de 1975, Caja 31.
} 
los trabajadores en fuerte ascenso, y con un movimiento obrero emergente que se definía como anticapitalista. La conjunción de estos factores creó entre los industriales un sentimiento de hostilidad y acoso agravado ante una próxima transición política con inciertos resultados en el plan económico y social. Así, surgió la propuesta de un pacto social para impedir la crisis del orden social que defendían. Para Economia, portavoz del Fomento del Trabajo, la situación política y social se había degradado a marchas forzadas,

lo que fuerza a que el anterior modelo o patrón de estructura económica deba ser objeto de una profunda revisión. En realidad [añadía] lo que se está debatiendo es una nueva jerarquía de valores dentro del mismo marco tradicional; pero en que éste sea formalmente democrático, parece que todo el mundo está de acuerdo [...]: Un pacto social sería una especie de contrato por el cual las clases favorecidas hasta el presente abdicaran conscientemente de algunos de sus privilegios y cedieran en sus posiciones de ventaja para ser compartidas por las clases trabajadoras; éstas a su vez considerarían el modelo neocapitalista como el campo de juego válido y aceptable, y se mantendrán pacíficamente dentro de él ${ }^{54}$.

Paralelamente, los industriales necesitaron también resituarse globalmente ante el nuevo panorama político, especialmente en lo relativo a la estructura asociativa. Para ello, debieron dar respuesta a tres necesidades: reforzar su organización, desvincularse del aparato sindical vertical y realizar una rápida "limpieza de imagen» que diluyera la difundida asociación «empresariosfranquistas». El reforzamiento organizativo podía hacerse sin dificultades debido a la existencia de sólidas organizaciones sectoriales, en tanto que para la desvinculación de la OSE y la creación de una cúpula patronal se disponía del Fomento del Trabajo Nacional. El 30 de septiembre de 1976 se reunió una asamblea de empresarios en el Palacio de Congresos de Barcelona, considerada como la refundación del Fomento; José Felipe Bertrán afirmó en ella:

Venimos aquí buscando encontrar un camino que nos resuelva una serie de nuevos problemas que se nos han creado (de un tiempo a esta parte) como consecuencia del rápido desmoronamiento de unas estructuras mantenidas durante prácticamente toda nuestra

${ }^{34}$ Economia (1975), núm. 1855. 
generación, lo que hacía que una serie de problemas nos los dieran resueltos sin intervención nuestra ${ }^{55}$.

El cambio de imagen no sería tan fácil, aunque igualmente imprescindible, como scñalaba un estudio encargado por el Instituto Industrial de Tarrasa al constatar, en relación al propio IIT, que

por ser la agrupación que agrupa a los empresarios-industriales, en el concepto de los últimos cuarenta años en España, pareciera ser que al Instituto no se le observa como «interlocutor válido" para el necesario diálogo y negociación con la parte laboral, por lo que conviene estar en cada instante pendiente de la evolución que está experimentando la actual Organización Sindical, para ir adecuando la desvinculación a ella con la intensidad y estrategia que cada momento aconseje, y sobre todo es imprescindible iniciar la etapa del «olvido» de la pertenencia del Instituto a tal organización. Se impone, concluyo, una «limpieza de antecedentes» ${ }^{56}$.

El sindicalismo vertical había sido una plataforma de actuación muy útil para los empresarios hasta los años setenta, y desprenderse de su asociación al franquismo era una necesidad que condicionó la trayectoria pública de numerosos dirigentes empresariales. En mayo de 1977 Carlos Ferrer Salat, que procedía del Círculo de Economía y de la Cámara de Barcelona, y no de la estructura sindical verticalista, por tanto «limpio de antecedentes», sería elegido presidente del Fomento del Trabajo Nacional para convertirse poco después en el primer presidente de la CEOE.

\section{Conclusiones}

En síntesis, para la burguesía industrial catalana la victoria franquista significó la restauración del orden social y su defensa mediante el «Nuevo Estado», que se propondría la definitiva destrucción de todos cuantos lo habían amenazado. De ahí vendría su «inquebrantable adhesión». Pero en el nuevo bloque dominante los industriales catalanes ocuparían un espacio periférico, lo que, añadido al carácter anticatalanista del régimen, condicionaría su capacidad de influencia en los aparatos del poder político.

ss CEAM (1976), núm. 138.

${ }^{56}$ AIIT, Diagnóstico y recomendaciones para el IIT, 2 de noviembre de 1976, Correspondencia 1976. 
Esa adhesión inquebrantable no era obstáculo para que, a lo largo de los años cuarenta, los sectores mejor representados en las entidades patronales fueron manifestando una actitud crítica hacia algunos aspectos importantes de la política económica y social, singularmente el intervencionismo en la economía, responsabilizándolo de muchos de los problemas más graves de la economía catalana y española. A partir de 1951 algunas de sus demandas fueron satisfechas, pero la quiebra de la política autárquica acentuó aún más sus peticiones de encauzar la economía por las vías de un capitalismo más ortodoxo.

La política económica iniciada a finales de los cincuenta significó un cambio que sintonizaba p'enamente con las aspiraciones de los industriales catalanes. Por primera vez desde 1939 la burguesía industrial se identificaba no sólo con el régimen político, sino con las líneas maestras de la política económica gubernamental. Ello, sin embargo, puso de manifiesto las contradicciones existentes entre los dirigentes patronales y muchos empresarios, para los cuales mayor libertad o intervención dependía exclusivamente de sus intereses más inmediatos. Estas contradicciones aparecían también ante la perspectiva de incorporación española a la CEE. El apoyo a la adhesión, prácticamente unánime en las organizaciones empresariales, si bien con ópticas no plenamente coincidentes, era mucho más ambiguo en la base empresarial.

Coincidiendo con la política de desarrollo económico, los industriales catalanes fueron especialmente críticos ante la creación de polos de desarrollo, el crecimiento del sector público y la falta de inversión en infraestructuras en el núcleo industrial barcelonés, así como con la protección al puesto de trabajo fijada en la legislación laboral, y, naturalmente, ante cuantas iniciativas, tanto económicas como sociales, fuesen intuidas como una limitación de la libertad de empresa.

Ante la creciente conflictividad laboral de los años sesenta fueron muy pocos los industriales que apostaron por un nuevo marco de relaciones laborales, recurriendo sistemáticamente a la represión, ejercida directamente o con el auxilio de las fuerzas policiales. Sólo cuando ésta alcanzó un grado elevado, paralelamente a la creciente influencia de un nuevo movimiento obrero, los sectores más representativos del empresariado industrial empezaron a distanciarse de la OSE, pidiendo mayores márgenes de negociación y el reconocimiento de derechos elementales de los trabajadores, aunque también una acción decidida contra los «agitadores políticos».

Los efectos de la crisis económica y la incertidumbre política provocaron a mitad de los setenta el hundimiento de las expectativas empresariales y el temor a una crisis que cuestionaría su preeminencia social. De ahí su coincidencia - después sistemáticamente silenciada - con la política gubernamental tendente a retrasar el impacto de la crisis económica mundial, y su pro- 
puesta de pacto social, formulada con angustia y casi como tabla de salvación.

La forma en que se realizó la transición española diluiría gradualmente los temores del empresariado _-el cambio político no iría acompañado de cambios socioeconómicos- y la rápida reconversión de sus estructuras asociativas le permitiría un notable protagonismo público, capaz de condicionar decisivamente la nueva etapa democrática.

\section{BIBLIOGRAFIA}

Aparicio, M. A. (1980): El Sindicalismo vertical y la formación del Estado tranquista, Barcelona, Eunibar.

Cámara Oficial de Comercio, Industria y Navegación de Barcelona (1971) y (1975): Memoria de Trahajos.

Cámara Oficial de Comercio y Navegación de Barcelona (1948), (1954-56) y (1957): Memoria de Trabajos.

Círculo DE Economís (1969): La politica económica a examen.

- (1972): Una Opinión de Actualidad, núm. 6.

Gremio de Fabricantes de Sabadell (1952), (1956) y (1968): Memorias.

HuErtas, J. M. (1982): Obrers a Catalunya, Barcelona, L'Avenç.

Ludevid, M. (1976): Cuarenta años de sindicato vertical, Barcelona, Laia.

Molinero, C. (1987): "Les entitats empresarials catalanes (1959-1976)», Revista de Catalunya, núm. 14.

Molinero, C., e Ysas, P. (1985): "Patria, Justicia y Pan». Nivell de vida $i$ condicions de treball a Catalunya 1939-1951, Barcelona, La Magrana.

SECEA (1959) y (1961): Boletin Informativo, núms. 117 y 163.

Tuse.ll, J. (1988): La dictadura de Franco, Madrid, Alianza. 